\title{
A Novel "FlocDrifter" Platform for Observing Flocculation and Turbulence Processes in a Lagrangian Frame of Reference
}

\author{
IAIN T. MACDONALD \\ National Institute of Water and Atmospheric Research, Hamilton, New Zealand \\ Julia C. Mullarney \\ Coastal Marine Group, Faculty of Science and Engineering, University of Waikato, Hamilton, New Zealand
}

(Manuscript received 20 May 2014, in final form 9 September 2014)

\begin{abstract}
A novel drifter platform was used to measure the properties of aggregated particles called flocs-a key component of sediment transport in muddy environments. Also concurrently measured were turbulence, suspended sediment concentration (SSC), velocity, and salinity in both Lagrangian and Eulerian frames of reference. In Lagrangian mode the system performed well in a heavily sediment-laden river, providing measurements over a large spatial scale. The platform navigated itself through a complex geometry encompassing many bends and significant depth changes. Observed velocities relative to the drifter and salinities indicated that the drifter motion was almost Lagrangian with minimal slippage between the drifter and the water motion. The small amount of slippage that did occur was sufficient to ensure that the drifter oriented itself into the oncoming flow.

High-quality in situ images of flocs were collected using a high-magnification floc camera (FlocCam). An automatic image analysis routine was developed to identify and characterize flocs within each FlocCam image, employing an artificial neural network (ANN) to ensure that only in-focus particles were included in the analyses. The results indicated that the FlocCam system had an upper working SSC limit of around 350$400 \mathrm{mg} \mathrm{L}^{-1}$.

The SSC estimates show that the drifters encountered considerable variability as they were advected downstream; however, concentrations predominantly remained under the image processing threshold of 350$400 \mathrm{mg} \mathrm{L}^{-1}$. The system captured the evolution of floc characteristics over short spatial scales (hundreds of meters). The median floc size $\left(d_{50}\right)$ was found to be positively correlated with SSC $\left(r^{2}=0.5\right)$. A comparison between Eulerian and Lagrangian floc histories can then be used to evaluate the role of antecedent conditions within the flocculation process.
\end{abstract}

\section{Introduction}

Aggregated particles (or flocs) are a key component of sediment transport in muddy environments, yet many of the intricacies of the flocculation process remain poorly understood. Floc size and characteristics control the floc settling velocity and need to be accurately elucidated to predict the movement of fine sediments in the aquatic environment. Flocs can form after collisions in which particles stick together (Burd and Jackson 2009). The likelihood of such collisions is increased in low to

Corresponding author address: Iain MacDonald, National Institute of Water and Atmospheric Research, P.O. Box 11115, Hillcrest, Hamilton 3251, New Zealand.

E-mail: iain.macdonald@niwa.co.nz moderately turbulent flow. Hence, these conditions promote aggregation, with flocs able to reach an equilibrium size if given sufficient time to evolve (Winterwerp 1998). Conversely, high levels of turbulence and shear can promote floc breakage (e.g., Milligan and Hill 1998; Hill et al. 2001; Fugate and Friedrichs 2003). These processes can also be modulated by the suspended sediment concentration (SSC; van Leussen 1999; Milligan et al. 2007).

Floc size has been successfully measured in both the laboratory and the field in an Eulerian frame of reference using floc cameras (Kranck and Milligan 1988; Milligan 1996; Hill et al. 1998; Mikkelsen et al. 2006; Smith and Friedrichs 2011; MacDonald et al. 2013) and laser diffraction [such as the Laser In Situ Scattering and Transmissometry (LISST) system; Bale and Morris 1987; Agrawal and Pottsmith 1994, 2000; Lynch et al. 1994; 
Bale 1996; Traykovski et al. 1999; Fugate and Friedrichs 2002; Andrews et al. 2010]. However, it has been shown that floc response to local conditions can be significantly influenced by the upstream conditions (such as turbulence and SSC). Braithwaite et al. (2012) found that particle size predictions matched well with the Winterwerp (1998) dynamical flocculation model if a phase lag (representing the adjustment time to changes in turbulence conditions) was included. Therefore, quantifying fine-sediment particle dynamics requires following particles in a Lagrangian framework to account for antecedent processes.

Currents in the ocean have been tracked using both surface and subsurface drifters for many years. A variety of designs have been utilized, from the pioneering drifters suitable for deep ocean deployments (Davis 1985) to those designed for estuarine, lake, and coastal environments (Johnson et al. 2003; Austin and Atkinson 2004). Recent designs include drifters for use in extremely shallow flows $(\sim 0.2 \mathrm{~m}$; Mullarney and Henderson 2013) and in the surf zone (Schmidt et al. 2003; MacMahan et al. 2009). Some of the latest developments also include drifters fitted with pulse coherent acoustic Doppler current profilers (ADCPs) to successfully provide Lagrangian estimates of the dissipation rate of turbulent kinetic energy (Mullarney and Henderson 2012; Thomson 2012).

Here, we combine a floc camera (FlocCam) and a drifter to take measurements of floc characteristics in a Lagrangian frame of reference. We present a novel design for the subsurface FlocDrifter, which is also equipped with a pulse coherent ADCP and an acoustic Doppler velocimeter (ADV) for velocity and turbulence measurements, a conductivity-temperature-depth (CTD) probe for measuring salinity, and an optical backscatter sensor (OBS) for estimating SSC. The system can be deployed in both Lagrangian and Eulerian modes to allow for separation of local and antecedent influences. We describe the platform design in section 2. Image processing methods are presented in section 3. The field deployments and results follow in section 4 . The results capture a substantial portion of the life cycle of flocs as they are advected downstream, along with corresponding collocated velocity, turbulence, salinity, and SSC measurements. Finally, the discussion and conclusions are given in section 5 .

\section{Design}

The FlocDrifter body (Figs. 1a,e) was constructed from stainless steel and consisted of an underwater housing for the FlocCam system connected to a stabilizing tail (925-mm length $\times 625$-mm height) made from a 6-mm-thick plastic sheet surrounded by a stainless steel frame. The design included purpose-built mounts for additional instruments: a Nortek Vector ADV, measuring the 3D velocity components at a single point; and a 2-MHz Nortek Aquadopp ADCP, operating in pulse-to-pulse coherent mode for 3D velocity measurements over a profile. Additionally, a Sea-Bird Electronics SBE-37 MicroCAT was mounted vertically at the end of the tail; above the camera housing, optical backscatter was measured using a Seapoint turbidity sensor; and an acoustic pinger was attached to the top of the tail. Measured and derived variables from each instrument are shown in Table 1. Additional stainless steel bars were welded at the front end to provide protection to the sensors in the event of a collision, and triangular bars were positioned underneath for ease of deployment and collection from small vessels. The overall length of the drifter was approximately $1740 \mathrm{~mm}$.

\section{a. FlocCam system}

The underwater housing (1010-mm length $\times 160$-mm internal diameter) contained a microprocessor (Arduino Uno) that automatically controlled a Canon EOS 550D digital single-lens reflex (SLR) camera. To achieve the required magnification, the camera was coupled to a Canon MP-E $65 \mathrm{~mm} \mathrm{f/2.8} \mathrm{1-5x} \mathrm{macro} \mathrm{photo} \mathrm{lens}$ (Fig. 1b). The housing also contained a $12-\mathrm{V}$ battery and a light opposite the camera (Fig. 1b). The microprocessor triggered the light and SLR to collect images at a fixed rate of around 1 every $2 \mathrm{~s}(0.5 \mathrm{~Hz})$. The camera was equipped with a 128-GB secure digital (SD) card and could record a maximum of $\sim 22000$ images before downloading, which equates to around $12 \mathrm{~h}$ of continuous operation at a capture rate of $0.5 \mathrm{~Hz}$. To increase the range of suspended sediment concentration over which the drifter could operate, a clear Perspex rod (60-mm diameter $\times 80 \mathrm{~mm}$ long) was inserted into the center of the flow-through region (Fig. 1b).

\section{b. Deployment modes}

When deployed in Lagrangian mode, the drifter was tethered to a surface float and swivel to keep the drifter at a fixed depth (top of wing: $\sim 1.5 \mathrm{~m}$ ) below the surface (Fig. 1c). A light and a Qstarz BT-Q1000eX GPS logger were placed on a small frame attached to the float with positions recorded at $10 \mathrm{~Hz}$. When deployed in Eulerian mode, the platform was attached to a weight on the seafloor and a subsurface float above (Fig. 1d).

\section{Image processing}

An automatic image analysis routine was developed to identify each floc within a FlocCam image. The automatic particle recognition system consisted of two main steps. The first step involved the segmentation of 

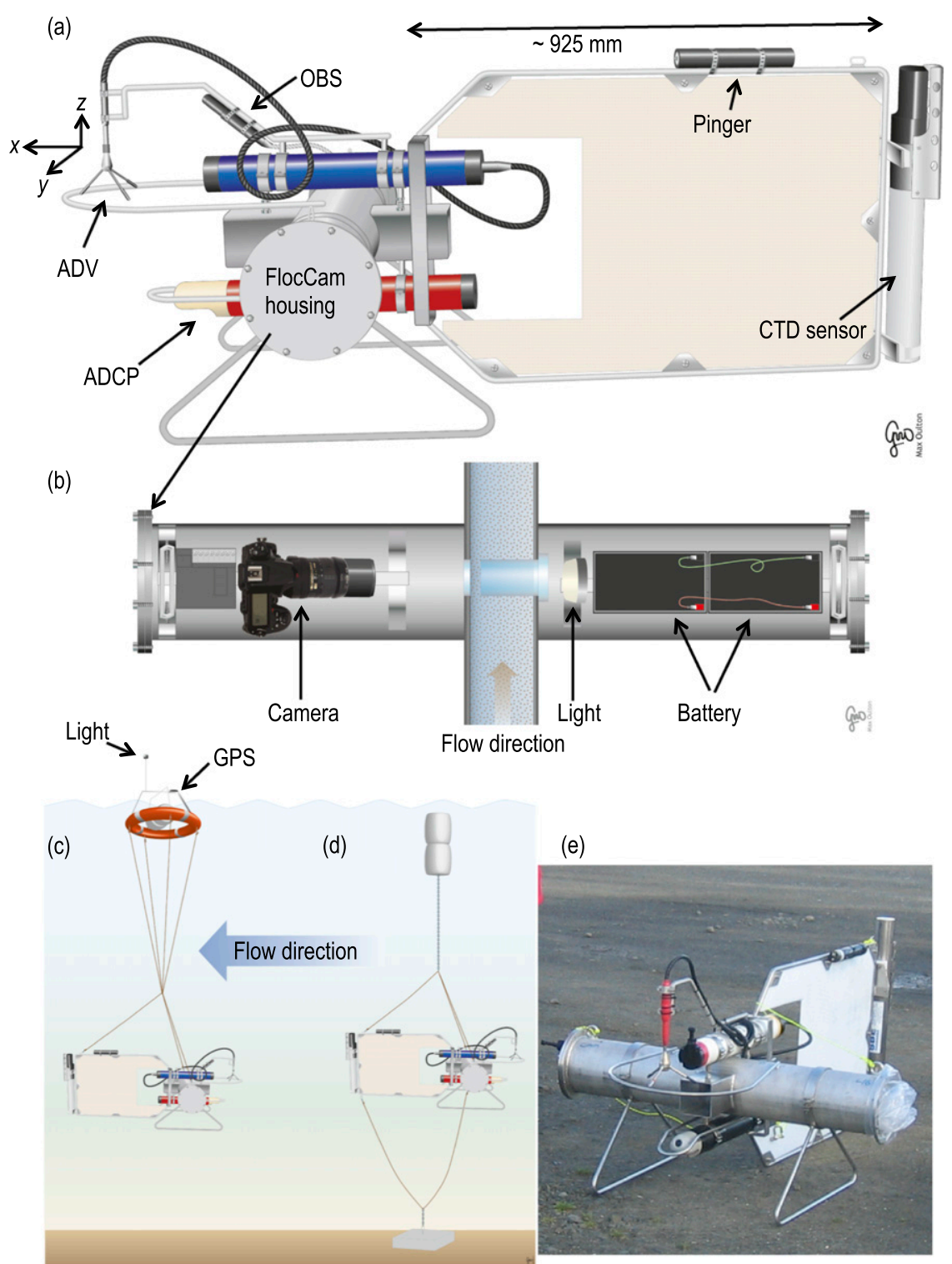

FIG. 1. Schematic of (a) the FlocDrifter body (approximately to scale), (b) the FlocCam system in underwater housing, and the complete FlocDrifter platform in (c) Lagrangian and (d) Eulerian deployment modes; and (e) photograph of drifter (before right-hand end cap of camera housing was attached). Arrows show the coordinate system relative to the ADV (see text for details).

each FlocCam image to distinguish individual particles from the background using the binary threshold method of Otsu (1979). In this method, the binary image forms a mask and various particle parameters (including size, shape, location, mean intensity, and two-dimensional projected area, $A$ ) are extracted for each identified particle. In the second step, an artificial neural network (ANN) was employed to ensure that only "in focus" particles are included in the analyses. The application of ANNs for image classification is extensive across many scientific disciplines such as meteorology, in which networks have been applied to classify cloud types (Bankert and Aha 1996). ANNs are also widely used in many aspects of medical imaging (Amartur et al. 1992; Jiang et al. 2010) and mineral engineering [e.g., for ore sorting and classification, as in Singh and Rao (2005)].

The ANN used a machine-learning algorithm to decide which of the particles identified during the segmentation step should be accepted or rejected from further analysis. In this study a single-hidden-layer feedforward ANN was used, composed of three layers - the input, and hidden and output layers (Fig. 2). The input 
TABLE 1. Summary of FlocDrifter instrumentation and variables measured. Elevation is relative to the center of the FlocCam field of view; a negative value represents an elevation below the field of view while a positive value represents an elevation above the field of view. List of symbols: PSD is the particle size distribution, $\varepsilon$ is the dissipation rate of turbulent kinetic energy, and SSC is the suspended sediment concentration.

\begin{tabular}{llcr}
\hline \hline \multicolumn{1}{c}{ Instrument } & \multicolumn{1}{c}{ Measured variables } & Derived variables & Elevation $(\mathrm{m})$ \\
\hline FlocCam & In situ floc images & PSD & 0.00 \\
ADV & 3D velocity components $u, v, w$ (single point) & & 0.00 \\
ADCP & 3D velocity components $u, v, w$ & & -0.213 to $-0.888(\Delta z=0.025)$ \\
& (profiles) & SSC & -0.263 to $-0.788(\Delta z=0.025)$ \\
Turbidity sensor & Optical backscatter & Salinity & 0.30 \\
SBE-37 MicroCAT & Conductivity and temperature & & 0.10 \\
\hline
\end{tabular}

layer contained $n$ input nodes corresponding to the $n$ independent input variables (predictors). Each of these nodes was connected to $m$ other nodes (neurons) in the hidden layer. Within each neuron the information from each input layer was transformed using (Oehler et al. 2012)

$$
h_{j}=f\left(a_{j}+\sum_{i=1}^{n} w_{j, i} x_{i}\right), \quad j=1,2, \ldots, m,
$$

where $h_{j}$ is the response of the $j$ th neuron, $a_{j}$ is the bias for the $j$ th neuron, $w_{j, i}$ is the weight connecting the $j$ th neuron and the $i$ th input node, and $x_{i}$ is the value from the $i$ th input node. The term $f$ in the above-mentioned equation represents the activation function, which effectively controls whether the neuron is "active" or "inactive." In this study the commonly used sigmoid activation function was selected. The output layer consisted of a simple node that performed like any of the neurons in the hidden layer, but rather than being fed information from the input layer, it took the output from each neuron (i.e., $h_{j}$ ) and applied a new set of weights and bias and a new activation function to generate the predictions. The ANN was developed by finding the set of weights that maximized the predictive capability of the ANN as assessed by comparison with a training dataset.

Textural features are one important class of parameters that are used to help identify objects or areas of interest within images. A typical approach (Haralick et al. 1973; Welch et al. 1988; Shokr 1991; Singh and Rao 2005) for characterizing texture within images is the use of the gray-level co-occurrence matrix (GLCM) first proposed by Haralick et al. (1973). The GLCM approach assumes that the textural information in any predefined region of an image is contained in the spatial relationships between the gray levels. From the GLCM Haralick et al. (1973) proposed 14 statistical parameters that characterize texture. In this study we employed the four most commonly used textural parameters: contrast (also known as inertia), correlation, energy (also known as uniformity or the angular second moment), and homogeneity. These four parameters were calculated for all particles identified during the segmentation step, and the values for the four parameters were used to define the input layer of the ANN. The output is binary, where a 0 represents an out-of-focus particle (not suitable for further analysis) and 1 represents an in-focus particle.

To calibrate the ANN, a calibration dataset is required. This dataset was assembled manually by identifying the in-focus and out-of-focus particles in a subset of randomly selected images. The output vector of ones and zeros formed the target dataset to which the ANN output is optimized. The four textural parameters that correspond to the manually identified particles were extracted and used to form the input layer in the calibration dataset. In line with best practice, when calibrating the ANN, the calibration dataset was randomly subsampled into three subsets: training $(70 \%$ of the calibration dataset), validation (15\%), and testing (15\%; Oehler et al. 2012). The training and validation datasets were used to calibrate the ANN. The validation dataset was required to avoid the problem of overtraining the ANN and the testing dataset is used to provide an independent estimate of the ANN performance. Once

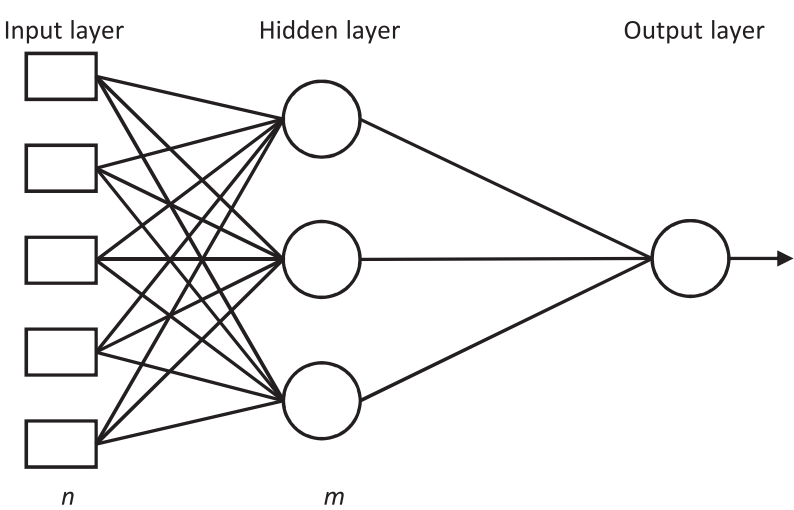

FIG. 2. Schematic diagram of a feed-forward ANN with $n$ input nodes (independent variables) and $m$ hidden nodes, and a single output node (dependent variable). 
calibrated, the ANN was fed the four input texture parameters for all particles identified during the segmentation step for each captured image. Given that slight lighting differences exist between FlocCams, an ANN was constructed for each drifter for each deployment day. Consequently, 13 calibration datasets and $13 \mathrm{ANNs}$ were assembled.

Summary statistics about the relative importance of the variables in the input layer of the 13 assembled ANNs are shown in Table 2. The relative importance (expressed as a percentage) for each input variable was calculated using (Lee et al. 2003; Singh et al. 2009)

$$
I_{i}=\frac{\sum_{j=1}^{m}\left|w_{j, i}\right|}{\sum_{k=1}^{n} \sum_{j=1}^{m}\left|w_{j, k}\right|} \times 100, \quad i=1,2, \ldots n
$$

Table 2 shows that typically all the textural features contributed significantly to the ANN with correlation showing the largest relative contribution and energy the smallest. The table also demonstrates that there was a reasonable amount of variability in the relative importance of each input variable across the 13 ANNs. This result is not surprising given the natural variability in the collected images, in part generated by slight lighting differences between FlocCams. Finally, a visual check of a series of images showed that the calibrated ANNs were reliably differentiating between in-focus and out-of-focus particles. All image processing was carried out in MATLAB using the image processing and neural network toolboxes.

At this stage of the analyses, quantities relating to particle size were expressed in pixel dimensions. To convert from pixel units to the International System of Units (SI units), the FlocCam was calibrated using images of a glass slide consisting of a grid of circles, each with an area of $3.06 \times 10^{-9} \mathrm{~m}^{2}$. From image analysis, the average number of pixels forming each circle could be established and hence the pixel-to-area ratio was determined. This analysis showed that the FlocCam had a pixel size of approximately $1.5 \mu \mathrm{m} \times 1.5 \mu \mathrm{m}$. From visual observations of the in-focus particles, particles with a diameter less than $10 \mu \mathrm{m}$ ( $\sim 40$ pixels) were rejected; below this limit particles were too small to be accurately resolved. In terms of an upper limit, the largest particle that FlocCam can resolve is determined by the field of view, which is approximately $7700 \mu \mathrm{m} \times 5100 \mu \mathrm{m}$. Hence, the largest (spherical) particle that could fit into the field of view would have a diameter of $\sim 5000 \mu \mathrm{m}$.

Because of the irregular morphologies of flocs (see Fig. 6), the definition of floc size is somewhat problematic.
TABLE 2. Summary statistics of the relative importance of the variables in the input layer of the 13 assembled ANNs.

\begin{tabular}{lccc}
\hline \hline Input variable & Mean $(\%)$ & Min $(\%)$ & Max $(\%)$ \\
\hline Contrast & 22 & 15 & 37 \\
Correlation & 43 & 29 & 51 \\
Energy & 17 & 5 & 29 \\
Homogeneity & 18 & 13 & 28 \\
\hline
\end{tabular}

Following the works of Manning and Bass (2006), Graham et al. (2012), and MacDonald et al. (2013), the definition of the equivalent spherical diameter was adopted, in which $d$ is given by

$$
d=\sqrt{\frac{4 A}{\pi}}
$$

\section{Field measurements}

\section{a. Field site}

Five drifters were tested over multiple days in the heavily sediment-laden Kaipara River on the North Island of New Zealand (Fig. 3a). The Kaipara River flows into the southern end of the mesotidal Kaipara Harbour (Fig. 3b). The river exhibits large bends, with frequent $180^{\circ}$ changes in direction, and is characterized by average depths along the thalweg of around $3 \mathrm{~m}$ but varying from 2 to $8 \mathrm{~m}$. Deployments took place during a period of low river flows $\left(4.3\right.$ decreasing to $2.6 \mathrm{~m}^{3} \mathrm{~s}^{-1}$ from the flow gauge at Waimauku, $\sim 25 \mathrm{~km}$ upstream of the drifter release location) over 3 days in October 2013. Up to three drifters were released shortly after high tide from varying locations, chosen to be sufficiently close together for sections of tracks to overlap, thus providing multiple measurements during different stages of the ebbing tide for some regions. Tracks covered sections of river measuring $4.1 \mathrm{~km}$ (with $3.8 \mathrm{~km}$ of overlapping sections $), 14.9 \mathrm{~km}(6.4 \mathrm{~km}$ overlapping), and $15.1 \mathrm{~km}(9.2 \mathrm{~km}$ overlapping) on days 1 , 2 , and 3, respectively (Fig. 3c shows the tracks from day $3)$. The GPS logger on the drifter released in the central section malfunctioned after $112 \mathrm{~min}$ on the second day; after this time, drifter positions have been estimated (when possible) from the GPS on the chase boat, which remained within about $50 \mathrm{~m}$ of the drifter throughout the deployment.

Two Eulerian FlocDrifter platforms (Fig. 1d) consisting of the FlocCam system but no ADCP or ADV were deployed at fixed locations (red triangles, Fig. 3c). Wind data were not recorded, but visual observations indicated that wind speeds were generally low throughout the duration of the experiments. 


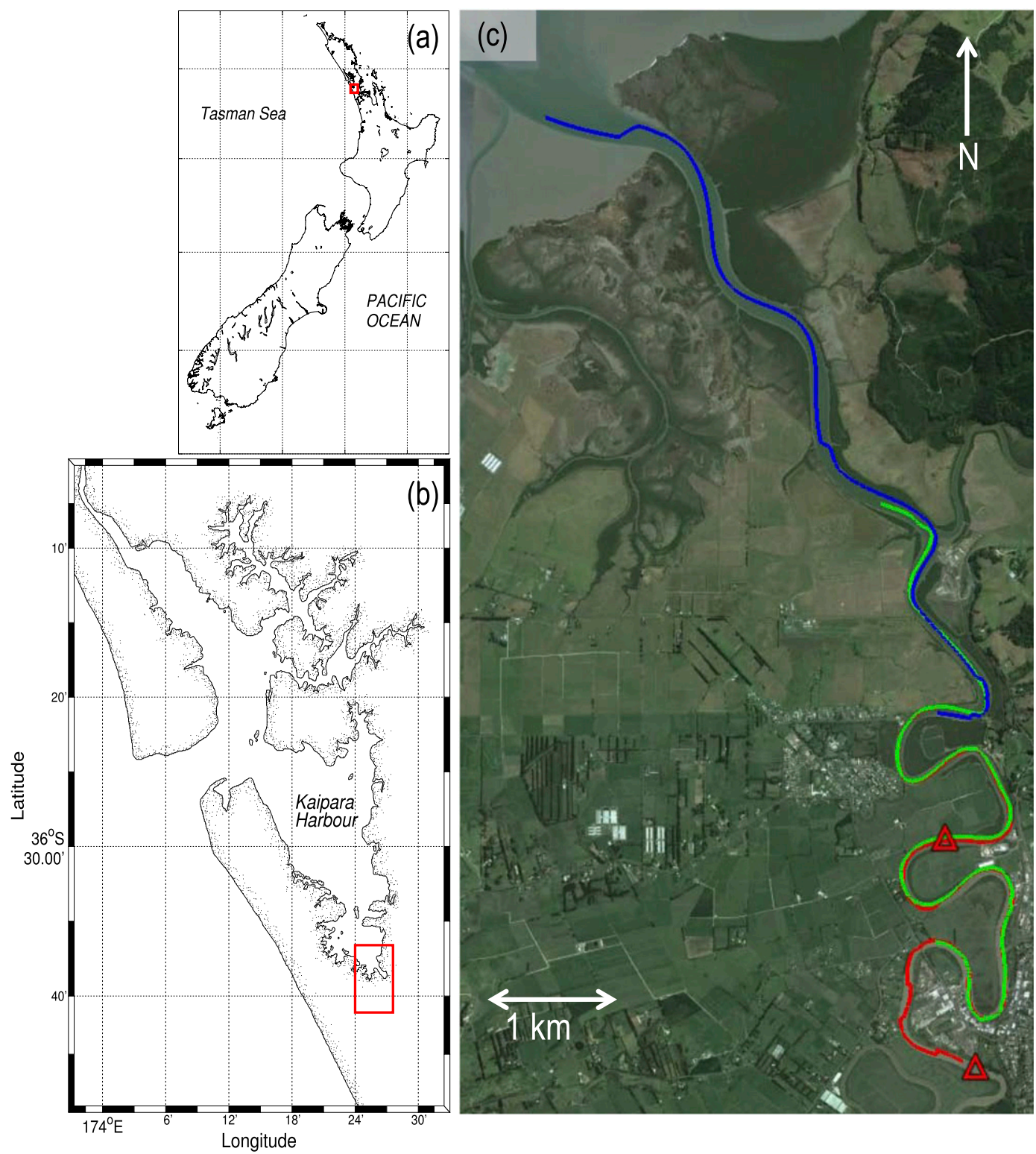

FIG. 3. (a) New Zealand with a small red box indicating the location of the Kaipara harbor. (b) Experiment location shown in the red rectangle. (c) Drifter tracks from day 3 superimposed on Google Earth Images. Colors indicate different drifters (all released at approximately the same time), and red triangles indicate the locations of the Eulerian platforms.

\section{b. Data acquisition and analysis}

ADCP velocities were recorded at $8 \mathrm{~Hz}$ over a $0.73-\mathrm{m}$ vertical profile in bins of along-beam size $27.6 \mathrm{~mm}$ (corresponding to a $25-\mathrm{mm}$ vertical bin size). Burst duration was $512 \mathrm{~s}$ with a 3 -s interval between bursts. Postprocessing followed similar data analysis methods found in Mullarney and Henderson (2012, 2013), but for completeness, the methods are summarized here. Bins with low correlations $(<50 \%)$ were removed from each beam before rotation to Earth coordinates [east-north-up (ENU)]. Relative horizontal drifter motion was accounted for by differencing the GPS positions (smoothed with a 1-s bin average and then a 20-s moving average filter) and then removing from ADCP-measured velocities. The location of the riverbed was identified from backscatter. There were some differences in backscatter between beams (likely owing to a tilted ADCP and/or small-scale bathymetric features on the riverbed), so the method of Mullarney and Henderson (2013) of removing drifter motion by using the apparent bed motion was not applicable here. An unwrapping routine was applied to 
remove the velocity ambiguities associated with use of pulse coherent instruments (see, e.g., Lhermitte and Serafin 1984; Lohrmann et al. 1990; Zedel et al. 1996). In a few regions (generally where water depths became very shallow), it was not possible to resolve the phase shift between pulses, leading to large potential errors in the velocity measurements. These periods have been removed. Times during which the drifter became stuck on features (e.g., on poles, piers, or the riverbed in very shallow regions) were identified as times with very low GPS velocities and/or large depth-averaged water motion relative to the drifter. These times corresponded well to observations made from the chase boats and these measurements were also discarded.

Estimates of the dissipation rate of turbulent kinetic energy $(\varepsilon)$ were obtained using the structure function method of Wiles et al. (2006) over 64-s windows (for windows in which over $50 \%$ of data passed the quality control thresholds mentioned above; Mullarney and Henderson 2012; Thomson 2012). Estimates were consistent between beams and when using different maximum separation distances for the structure function fit (between 83 and $166 \mathrm{~mm}$ or 3-6 range bins). Reported results are the mean over all beams (which passed the quality control criteria) and are shown for fits over the maximum separation distance of $110 \mathrm{~mm}$ (four range bins).

The Nortek Vector velocimeters all recorded velocity continuously at $16 \mathrm{~Hz}$ in instrument coordinates. Postprocessing removed times when the drifter was stuck and then discarded times $(<2.5 \%$ of data) when any beam had low $(<90 \%)$ correlations or low $(<20)$ signalto-noise ratio. The data were also despiked by removing times with unrealistically large velocity magnitudes $\left(>0.25 \mathrm{~m} \mathrm{~s}^{-1}\right)$.

The optical backscatter was recorded continuously at $5 \mathrm{~Hz}$. The voltage output by the optical backscatter sensor $(V)$ was related to the SSC by a linear relationship:

$$
\mathrm{SSC}=G V+O,
$$

where $G$ is the sensor gain ( $\mathrm{mg} \mathrm{L}^{-1}$ per volt) and $O$ is the sensor offset $\left(\mathrm{mg} \mathrm{L}^{-1}\right)$. The sensor gain and offset were determined by calibrating the sensor against a series of test suspensions of a known concentration in the laboratory. The sediment used in the calibration came from a $\sim 100-\mathrm{L}$ water sample collected at the field site in a region of high SSC. The sediment was allowed to settle to the bottom of the container over a period of 7 days, during which time the water sample was stored in the dark at $1^{\circ} \mathrm{C}$ to inhibit any biological activity. After the sediment had settled, the supernatant was decanted off, leaving a concentrated slurry that was used for the calibration process. The calibration dataset was generated by the incremental addition of the concentrated slurry into a well-mixed 30-L recirculating tank. The reference concentration was measured gravimetrically after each extra addition of sediment. A regression was used to fit the linear relationship [Eq. (4)] to the calibration dataset to determine $G$ and $O$. To verify this approach, water samples were collected in the field near the OBS sensors. A comparison between suspended sediment concentrations obtained from the gravimetric analysis of 51 water samples and the predicted values [i.e., using Eq. (4)] showed only small differences (usually less than $10 \%)$.

The Sea-Bird Electronics SBE-37 MicroCATs all recorded CTD data at a rate of one sample every $6 \mathrm{~s}$ $(0.167 \mathrm{~Hz})$. Practical salinity $\left(S_{p}\right)$ was determined from the CTD data using a modified form of the Practical Salinity Scale 1978 equation (Hill et al. 1986).

\section{c. Velocities and turbulence}

The ADV was oriented with the $x$ axis pointing directly away from the drifter (e.g., to the left in Fig. 1a). Observed velocities relative to the ADVs were small along all axes (median values across deployments from all drifters of $-0.018,-0.0024$, and $-0.0022 \mathrm{~m} \mathrm{~s}^{-1}$ in the $x, y$, and $z$ directions, respectively), indicating that the drifter motion was almost Lagrangian with minimal slippage between the drifter and the water motion (Fig. 4). However, the small amount of slippage that did occur was sufficient to ensure that the drifter oriented itself into the oncoming flow with the tail opposite of the direction of motion (upstream in the river sense), as indicated by the negative $x$-velocity values that were an order of magnitude larger than the $y$ or $z$ velocities. Standard deviations of velocities were still relatively large however, indicating substantial variability within the flow (Fig. 4).

Measurements from the drifter released in the central part of the river (green line, Fig. 3) are shown in Fig. 5. For ease of comparison, the position along track has been mapped to a path along the center of the river, starting at the most-upstream release point. Water velocities were generally depth uniform over the short profile length measured (Fig. 5c) and of order $0.6 \mathrm{~m} \mathrm{~s}^{-1}$, which were also consistent with the GPS measurements of drifter speed, again indicating near-Lagrangian motion. However, there are occasionally periods of considerable velocity shear over the profile (predominantly occurring in upstream- and downstream-released drifters; tracks not shown). Generally, the quality of the ADCP data was excellent except in small bands of pulse-to pulse interference (Fig. 5b). As in Mullarney and Henderson (2013), small wind waves could be discerned in the data (not shown here). Dissipation rates of turbulent kinetic 

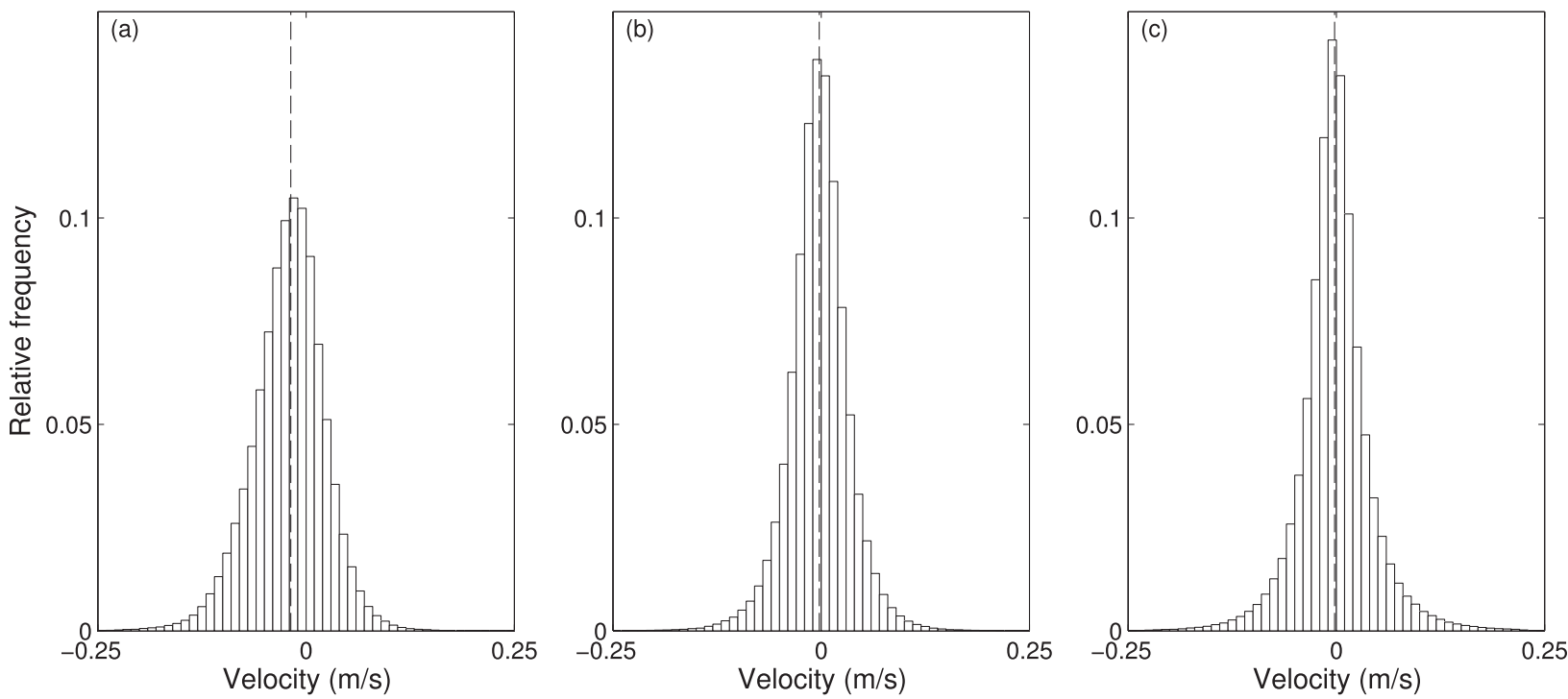

FIG. 4. Histograms of relative frequencies (fraction of all observations) of (a) $x$, (b) $y$, and (c) $z$ velocities relative to the ADV from all drifters over all deployments. The vertical dashed lines indicate median values.

energy ranged from $O\left(10^{-7}\right)$ to $O\left(10^{-3.4}\right) \mathrm{W} \mathrm{kg}^{-1}$ with a slight tendency to increase downstream as the water depth decreased. These dissipation rates correspond to Kolmogorov length scales of around $200-1800 \mu \mathrm{m}$ and to shear rates of around $0.30-20 \mathrm{~s}^{-1}$. The observed dissipation rates are similar to the values observed by Mullarney and Henderson (2012) over a shallow tidal flat. Although the calculations of $\varepsilon$ were made from depths of 0.213 $0.888 \mathrm{~m}$ below the camera, the results generally do not indicate a strong variation over the measurement profile (Fig. 5d). Hence, it is likely that dissipation rates at the location of the floc measurements are similar to those at the top of the profile. Unsurprisingly, high backscatter counts were correlated with higher SSC.

\section{d. Salinity}

Salinity estimates for the central drifter on day 3 are shown in Fig. 5e. The measurements typically show that the drifters encountered very little variation in salinity as they were advected downstream, again suggesting that the drifter motion followed the water motion closely. Large jumps in salinity were found to coincide with times at which the drifter was repositioned by the chase boat from the channel margin to the center of the channel, implying the existence of significant lateral variations in salinity.

Generally salinities were low: in the upstream and central sections, the salinity never exceeded 2 psu, whereas in the downstream section the salinities were typically around $10.5 \mathrm{psu}$, with a tendency for the salinity along each track to increase with distance downstream.

\section{e. Floc measurements}

Figure 6 shows a series of FlocCam images taken over a range of SSC. The figure shows images taken from two different drifters: the images shown in the top two rows were taken from a drifter operating in Lagrangian mode, while the bottom two rows show images collected while a drifter was operating in Eulerian mode. The images were selected to cover a wide range of SSC, to demonstrate image quality. It is worth noting that the Lagrangian and Eulerian images shown in Fig. 6 were collected on different days; that is, these are not concurrent measurements. The images show that the FlocCam is capable of producing high-quality floc images well suited to image analysis techniques while operating in both modes. The images tend to suggest an upper working SSC of around $400 \mathrm{mg} \mathrm{L}^{-1}$; above this concentration it becomes increasingly difficult to identify individual flocs within the image, and thus such concentrations may not be suitable for automated image analysis. The images also show an apparent increase in floc size with increasing SSC.

Figure 7 shows the particle size distribution (PSD) obtained at nominal SSCs of 100, 200, 300, 400, and $500 \mathrm{mg} \mathrm{L}^{-1}$. The figure shows PSDs derived from the images collected by two different drifters. The left (right) column corresponds to a Lagrangian (Eulerian) deployment. The results from the Lagrangian and Eulerian deployments are from different days. The PSDs were derived from all in-focus particles that were identified by the image analysis routine over a 5-min observation window (150 images). The PSDs in Fig. 7 show a shift toward larger particles as the SSC increased from 
(a)
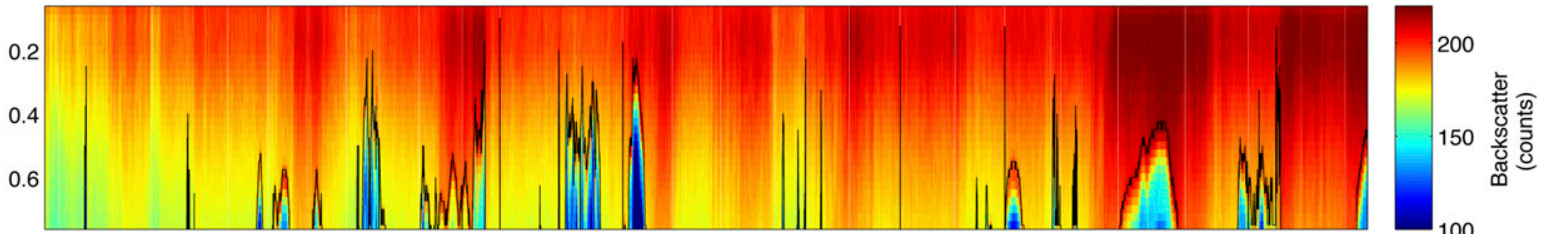

(b)

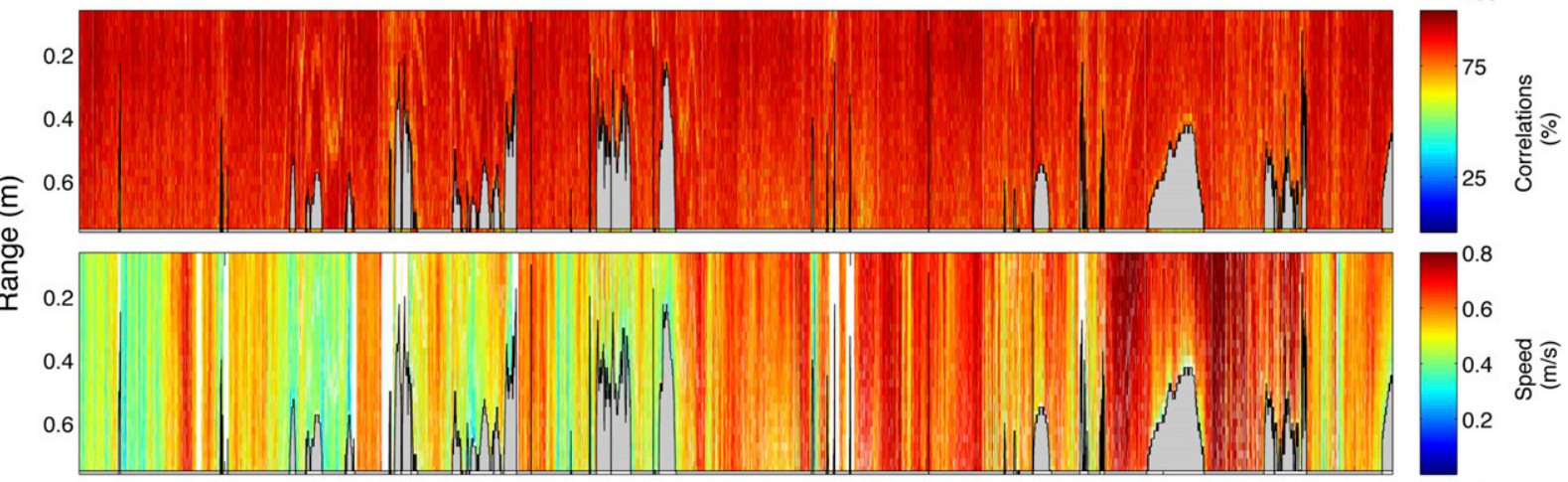

(d)

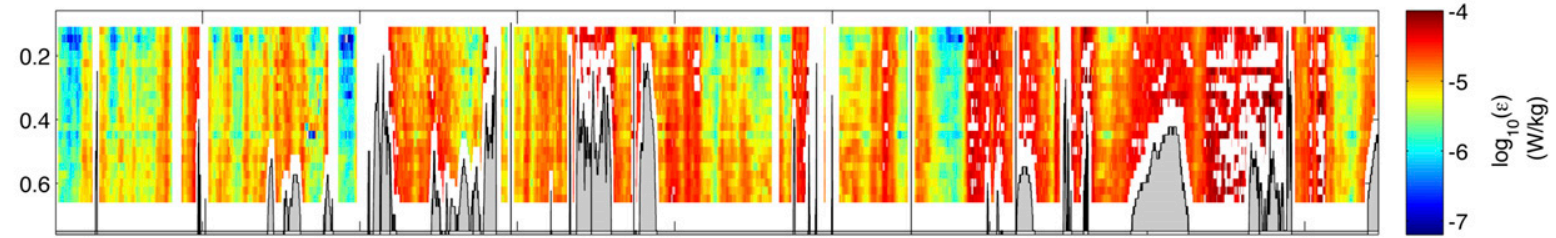

(e)

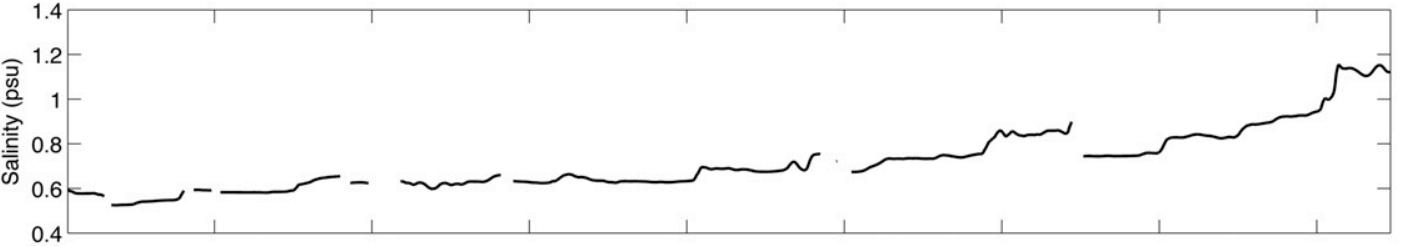

(f)

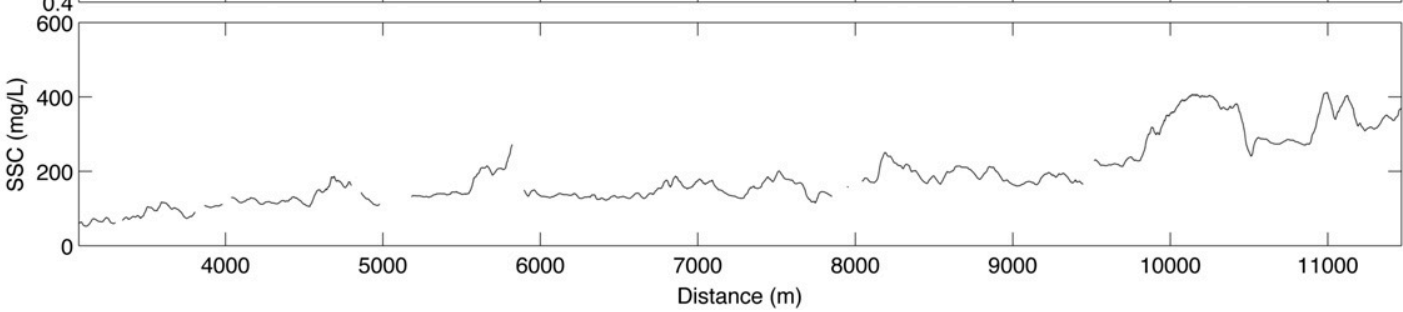

FIG. 5. Data from the ADCP and CTD sensors on the drifter released in the central section of the river on day 3 (green line, Fig. $3 \mathrm{c}$ ). (a) Backscatter (counts, mean over three beams) with bottom indicated by black lines, (b) correlations (\%, mean over three beams), (c) horizontal velocity magnitude $\left(\mathrm{m} \mathrm{s}^{-1}\right)$, (d) dissipation rate of turbulent kinetic energy $\left(\log _{10} \mathrm{~W} \mathrm{~kg}^{-1}\right)$, (e) salinity (psu), and (f) suspended sediment concentration $\left(\mathrm{mg} \mathrm{L}^{-1}\right)$. White sections in (c) and (d) indicate bad data. Values in (e) and (f) were smoothed with a 64-s running mean. The abscissa shows the distance along river from the most-upstream release point. For this drifter release, the SSC estimates were determined from the ADV backscatter calibrated against in situ water samples owing to a malfunctioning OBS sensor.

100 to $400 \mathrm{mg} \mathrm{L}^{-1}$. This trend is consistent with a visual comparison of the images collected over these periods (Fig. 6). At $500 \mathrm{mg} \mathrm{L}^{-1}$ there would appear to be a small shift toward smaller particles; however, this apparent decrease in particle size is not consistent with visual observations. This decrease in the PSD most likely results from obscuration of the particles, which in turn causes an underestimation in the size of the particles detected by the image analysis routines. From this result we conclude that the drifters have an upper working SSC threshold of around $400 \mathrm{mg} \mathrm{L}^{-1}$, which is the same as the upper threshold of Smith and Friedrichs (2011). Above these concentrations, the images may still yield some useful information about particle sizes but a far greater level of manual processing would be required. The manual processing of the images is not considered here.

A comparison of the PSD measured under the Lagrangian and Eulerian deployment modes for concurrent measurements are presented in Fig. 8. The PSDs (Figs. 8a,b) were derived from all in-focus particles that 

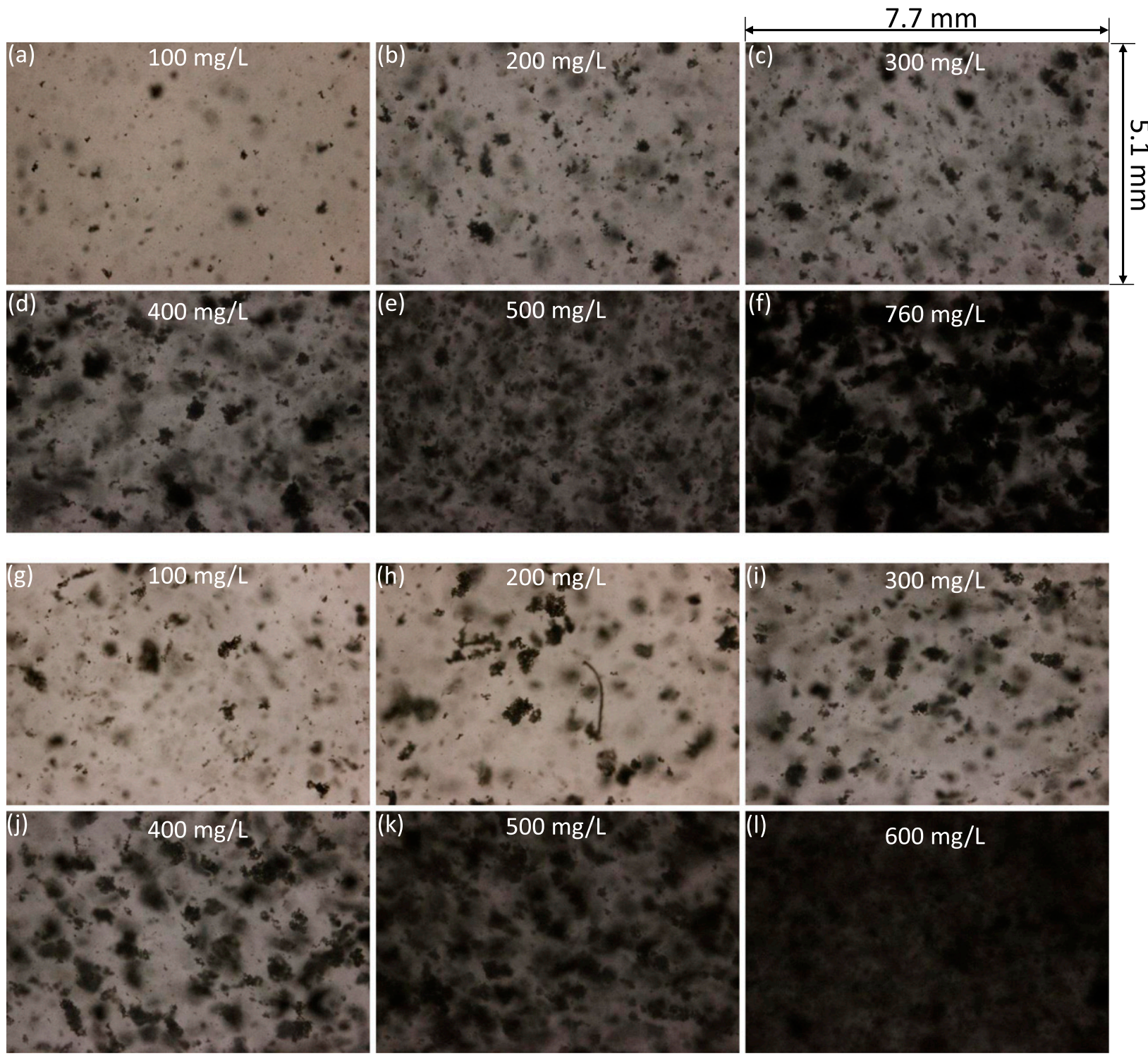

FIG. 6. FlocCam images over a range of nominal SCCs: taken while operating in (a)-(f) Lagrangian mode and (g)-(l) Eulerian mode. The field of view is approximately $5.1 \mathrm{~mm} \times 7.7 \mathrm{~mm}$ in all images.

were identified by the image analysis routine over a 5-min observation window (150 images). The end of the observation window corresponded to the moment in time when the Lagrangian drifter passed by the Eulerian drifter; thus, the particles advected past the Eulerian drifter are expected to be similar to those encountered by the Lagrangian drifter over the observation window. From the PSDs and the cumulative frequency distributions shown in Fig. 8, it is apparent that the two distributions are indeed very similar with only small differences between the two (the median particle sizes in Fig. $8 \mathrm{c}$ were $d_{50}=84$ and $89 \mu \mathrm{m}$ for the Lagrangian and Eulerian measurements, respectively). This significant result provides a reasonable level of confidence that the PSD can be accurately measured while operating under both deployment modes.

\section{f. Suspended sediment concentrations}

SSC estimates for the central section of the river for day 3 are shown in Fig. 5f; unfortunately, the OBS logger on the drifter released in the central section malfunctioned on this day, so in this case SSC were estimated from the ADV backscatter calibrated against in situ water samples. The SSC estimates show that both drifters encountered considerable variability in SSC as they were advected downstream. At both release sites, 

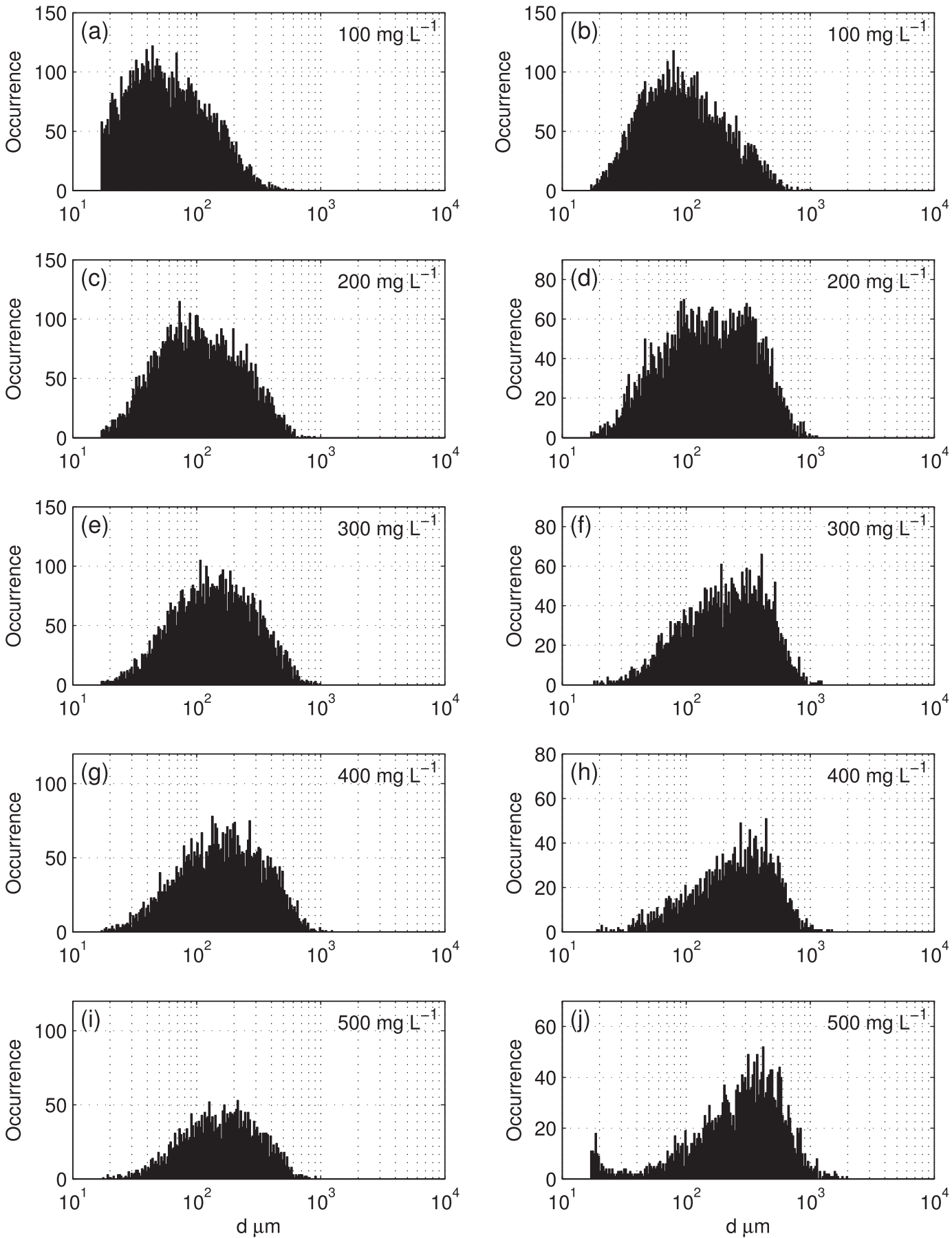

FIG. 7. Measured particle size distributions over a range of (nominal) suspended sediment concentrations. The left (right) column corresponds to a Lagrangian (Eulerian) deployment. (a),(b) $100 \mathrm{mg} \mathrm{L}^{-1}$, (c),(d) $200 \mathrm{mg} \mathrm{L}^{-1}$, (e),(f) $300 \mathrm{mg} \mathrm{L}^{-1},(\mathrm{~g})$,(h) $400 \mathrm{mg} \mathrm{L}^{-1}$, and (i),(j) $500 \mathrm{mg} \mathrm{L}^{-1}$. A direct comparison between columns is not possible as measurements are from different times and locations. Note the varying scales on the $y$ axes.

the overall trend shows that SSC increases with distance downstream. Crucially, the SSC estimates remained below the image processing threshold of $350-400 \mathrm{mg} \mathrm{L}^{-1}$ for the majority of the deployments.

\section{Discussion and conclusions}

A novel drifter platform was used to measure floc and hydrodynamic properties over a large spatial scale in 

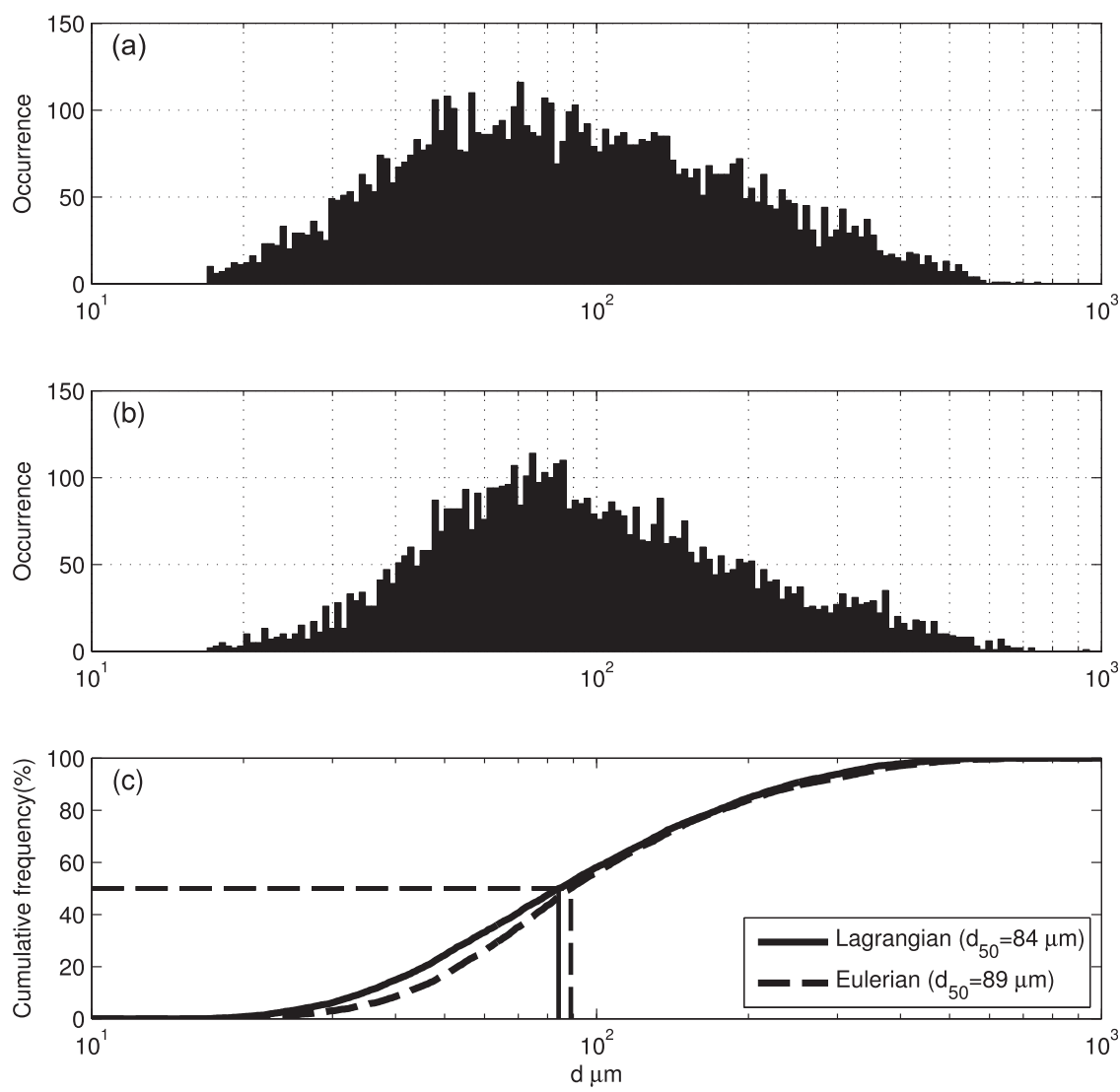

FIG. 8. PSDs measured by two drifters while operating under different deployment modes: (a) Lagrangian and (b) Eulerian modes, and (c) cumulative frequency distributions.

a heavily sediment-laden tidal river. The system was demonstrated to perform well in both Lagrangian and Eulerian frames of reference. The platform navigated itself through a complex geometry encompassing many bends and significant depth changes, although constant observation was required to release the platform in the case of entanglement. The frame at times proved somewhat cumbersome to deploy from a small boat; however, this disadvantage was offset by providing significant flexibility for mounting of additional instrumentation.

The measurements revealed significant along-river variation over scales of a few hundred meters, which would unlikely have been resolved without a very large array of Eulerian measurements. Horizontal water velocities and turbulence were measured using an ADCP operating in pulse coherent mode and an ADV (vertical velocities can only be resolved when the riverbed is within the depth range of the ADCP; Mullarney and Henderson 2013). The quality of the ADCP data was generally excellent except in small bands of pulse-topulse interference. Dissipation rates of turbulent kinetic energy ranged from $O\left(10^{-7}\right)$ to $O\left(10^{-3.4}\right) \mathrm{W} \mathrm{kg}^{-1}$ with a slight tendency to increase downstream as the water level decreased (as drifters were released on flood tide). The observed velocities relative to the ADVs were small along all axes, indicating minimal slippage between the drifter and the moving water column. The Lagrangian nature of the drifter trajectories was further supported by the near uniformity of salinity measurements along the drifter tracks. The small amount of slippage that did occur was sufficient to ensure that the drifter oriented itself into the oncoming flow.

High-quality in situ images of flocs were collected using a high-magnification floc camera (FlocCam). An automated image analysis routine was developed to identify and characterize each floc within the FlocCam images. The automatic particle recognition system consisted of two stages: segmentation of the FlocCam images to distinguish individual particles from the background and the employment of an artificial neural network (ANN) to ensure that only "in focus" particles were included in the analyses. A comparison of the particle size distribution measured under the Lagrangian and Eulerian deployment modes over the same observation window showed only minor differences, thus providing a significant level of confidence that the PSD 

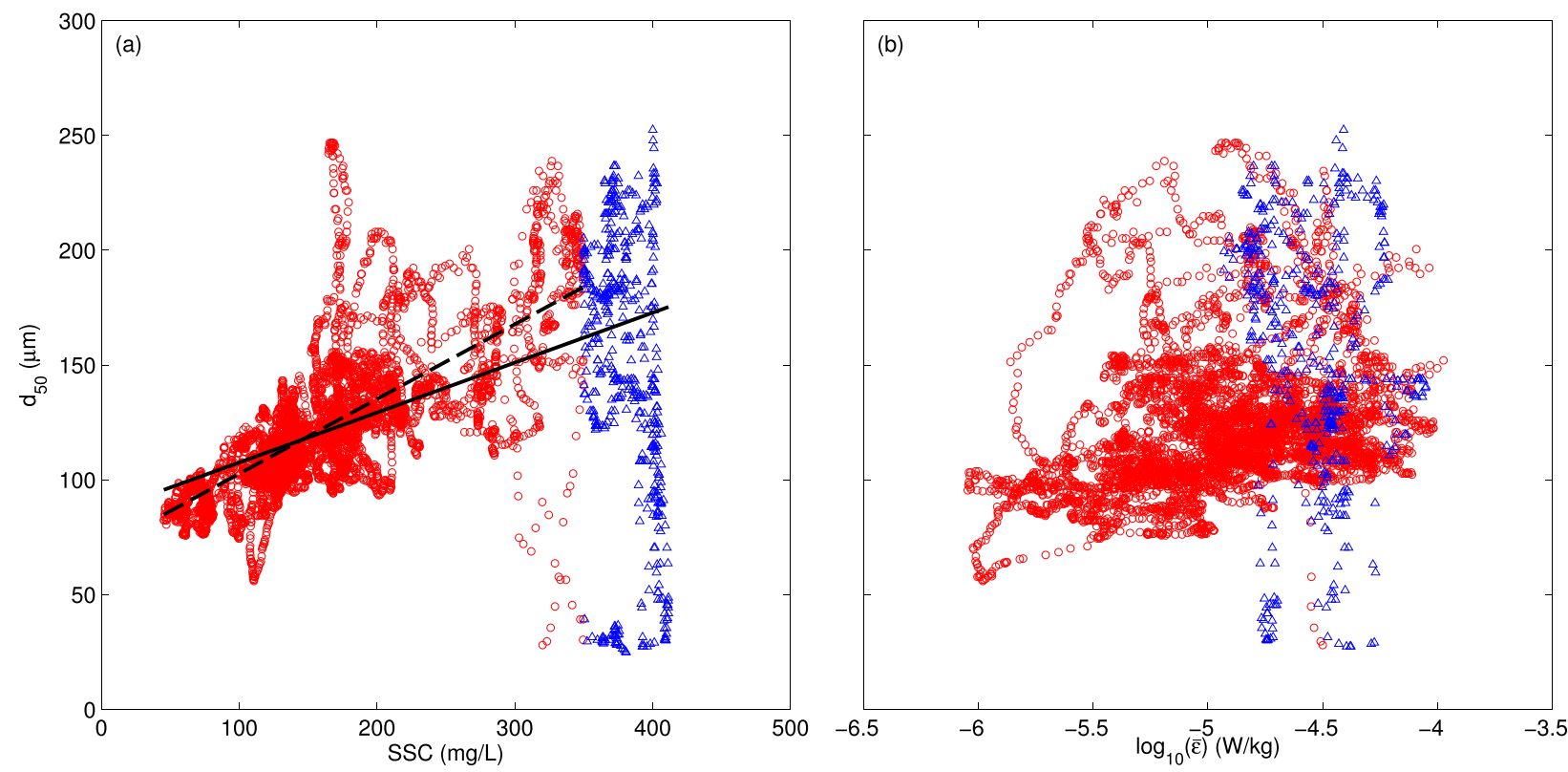

FIG. 9. Median floc sizes $d_{50}$ vs (a) SCCs and (b) vertically averaged (over profile) dissipation rates of $\varepsilon$ for the drifter released in the central section of the river on day 3 (green line in Fig. 3c and corresponding to measurements shown in Fig. 5). Symbols show data for which for SSC $<350 \mathrm{mg} \mathrm{L}^{-1}$ (red circles) and SSC $\geq 350 \mathrm{mg} \mathrm{L}^{-1}$ (blue triangles). In (a) linear fits are shown for data below the concentration threshold value (dashed line) and all data (solid line).

can be accurately measured while operating under both deployment modes. Further analysis revealed that the drifters have an upper working SSC threshold of around $350-400 \mathrm{mg} \mathrm{L}^{-1}$. Above this threshold, the manual processing of images could perhaps be used to yield some useful information about particle sizes; however, this possibility has not been addressed here.

Unlike salinity, SSC estimates show that the drifters experience considerable variability in SSC as they were advected downstream. The variability in SSC most likely results from the spatial and temporal changes in sediment sources (e.g., erosion) and sediment sinks (e.g., deposition). Crucially, the SSC estimates rarely exceed the image processing threshold of $350-400 \mathrm{mg} \mathrm{L}^{-1}$. Preliminary analysis indicates that median floc size is positively correlated with SSC (Fig. 9), although there is some scatter particularly at higher SSCs. This result held for both Eulerian and Lagrangian drifters. A linear fit between $d_{50}$ and SSC for the data in Fig. 9 yielded $r^{2}$ values of 0.3 (all data) and 0.5 (data for which SSC $<$ $350 \mathrm{mg} \mathrm{L}^{-1}$ ). Further work will explore the possible causes of variability around the fitted relationships. No clear relationship between median floc size and (depth averaged over the profile) dissipation rate of turbulent kinetic energy could be discerned (Fig. 9b). However, for flocs under the concentration threshold (SSC < $350 \mathrm{mg} \mathrm{L}^{-1}$ ), the data are weakly suggestive of an increase in the largest median floc size at a given turbulence level up to $\varepsilon \sim 10^{-5} \mathrm{~W} \mathrm{~kg}^{-1}$, but higher turbulence levels corresponded to a decrease in maximum $d_{50}$, consistent with the classical conceptual model of floc formation and breakup. A detailed investigation into the connection between present and past environmental conditions (turbulence, SSC, and salinity) and floc size will be the subject of a future manuscript.

Acknowledgments. This work was supported by NIWA's core program, Catchment to Estuaries, in the Freshwater and Estuaries Centre, and by the Cumulative Effects of Contaminants on Aquatic Ecosystem Program C01×1005 funded by the Ministry of Business, Innovation, and Employment. We thank Dave Bremner, Rod Budd, Scott Edhouse, Sam Parkes, Mark Pritchard, and Glen Reeve for their assistance with the field work. We also acknowledge Dave Bremner, Mark Smith, and Richard Yates for their role in the development and construction of the drifters. The authors also thank Dr. Malcolm Green for his valuable input into the manuscript. The authors thank the reviewers of an earlier version of this manuscript for their valuable comments and suggestions, which were incorporated into this revised version.

\section{REFERENCES}

Agrawal, Y. C., and H. C. Pottsmith, 1994: Laser diffraction particle sizing in stress. Cont. Shelf Res., 14, 1101-1121, doi:10.1016/ 0278-4343(94)90030-2. 
- , and -2000 : Instruments for particle size and settling velocity observations in sediment transport. Mar. Geol., 168, 89-114, doi:10.1016/S0025-3227(00)00044-X.

Amartur, S. C., D. Pirainp, and Y. Takefuji, 1992: Optimization neural networks for the segmentation of magnetic resonance images. IEEE Trans. Med. Imaging, 11, 215-220, doi:10.1109/ 42.141645.

Andrews, S., D. Nover, and S. G. Schlado, 2010: Using laser diffraction data to obtain accurate particle size distributions: The role of particle composition. Limnol. Oceanogr. Methods, 8, 507-526, doi:10.4319/lom.2010.8.507.

Austin, J., and S. Atkinson, 2004: The design and testing of small, low-cost GPS-tracked surface drifters. Estuaries, 27, 10261029, doi:10.1007/BF02803428.

Bale, A. J., 1996: In situ laser optical particle sizing. J. Sea Res., 36, 31-36, doi:10.1016/S1385-1101(96)90767-4.

_- and A. W. Morris, 1987: In situ measurement of particle size in estuarine waters. Estuarine Coastal Shelf Sci., 24, 253-263, doi:10.1016/0272-7714(87)90068-0.

Bankert, R. L., and D. W. Aha, 1996: Improvement to a neural network cloud classifier. J. Appl. Meteor., 35, 2036-2039, doi:10.1175/1520-0450(1996)035<2036:ITANNC>2.0.CO;2.

Braithwaite, K. M., D. G. Bowers, W. A. M. Nimmo Smith, and G. W. Graham, 2012: Controls on floc growth in an energetic tidal channel. J. Geophys. Res., 117, C02024, doi:10.1029/ 2011JC007094.

Burd, A. B., and G. A. Jackson, 2009: Particle aggregation. Annu. Rev. Mar. Sci., 1, 65-90, doi:10.1146/annurev.marine.010908.163904.

Davis, R. E., 1985: Drifter observations of coastal surface currents during CODE: The method and descriptive view. J. Geophys. Res., 90, 4741-4755, doi:10.1029/JC090iC03p04741.

Fugate, D. C., and C. T. Friedrichs, 2002: Determining concentration and fall velocity of estuarine particle populations using ADV, OBS and LISST. Cont. Shelf Res., 22, 1867-1886, doi:10.1016/S0278-4343(02)00043-2.

- , and $—, 2003$ : Controls on suspended aggregate size in partially mixed estuaries. Estuarine Coastal Shelf Sci., 58, 389404, doi:10.1016/S0272-7714(03)00107-0.

Graham, G. W., E. J. Davies, W. A. M. Nimmo-Smith, D. G. Bowers, and K. M. Braithwaite, 2012: Interpreting LISST100X measurements of particles with complex shape using digital in-line holography. J. Geophys. Res., 117, C05034, doi:10.1029/2011JC007613.

Haralick, R. M., K. Shanmugam, and I. Dinstein, 1973: Textural features for image classification. IEEE Trans. Syst. Man Cybern., SMC-3, 610-621, doi:10.1109/TSMC.1973.4309314.

Hill, K. D., T. Dauphinee, and D. J. Woods, 1986: The extension of the practical salinity scale 1978 to low salinities. IEEE J. Oceanic Eng., 11, 109-112, doi:10.1109/JOE.1986.1145154.

Hill, P. S., J. P. Syvitski, E. A. Cowan, and R. D. Powell, 1998: In situ observations of floc settling velocities in Glacier Bay, Alaska. Mar. Geol., 145, 85-94, doi:10.1016/S0025-3227(97)00109-6.

—, G. Voulgaris, and J. H. Trowbridge, 2001: Controls on floc size in a continental shelf bottom boundary layer. J. Geophys. Res., 106, 9543-9549, doi:10.1029/2000JC900102.

Jiang, J., P. Trundle, and J. Ren, 2010: Medical image analysis with artificial neural networks. Comput. Med. Imaging Graphics, 34, 617-631, doi:10.1016/j.compmedimag.2010.07.003.

Johnson, D., R. Stocker, R. Head, J. Imberger, and C. Pattiaratchi, 2003: A compact, low-cost GPS drifter for use in the oceanic nearshore zone, lakes, and estuaries. J. Atmos. Oceanic Technol., 20, 1880-1884, doi:10.1175/1520-0426(2003)020<1880: ACLGDF $>2.0 . \mathrm{CO} 2$
Kranck, K., and T. G. Milligan, 1988: Macroflocs from diatoms: In situ photography of particles in Bedford Basin, Nova Scotia. Mar. Ecol.: Prog. Ser., 44, 183-189, doi:10.3354/ meps044183.

Lee, J. H., Y. Huang, M. Dickman, and A. Jayawardena, 2003: Neural network modelling of coastal algal blooms. Ecol. Modell., 159, 179-201, doi:10.1016/S0304-3800(02)00281-8.

Lhermitte, R., and R. Serafin, 1984: Pulse-to-pulse coherent Doppler sonar signal processing techniques. J. Atmos. Oceanic Technol., 1, 293-308, doi:10.1175/1520-0426(1984)001<0293: PTPCDS $>2.0 . \mathrm{CO} ; 2$

Lohrmann, A., B. Hackett, and L. P. Røed, 1990: High resolution measurements of turbulence, velocity and stress using a pulse-to-pulse coherent sonar. J. Atmos. Oceanic Technol., 7, 19-37, doi:10.1175/1520-0426(1990)007<0019: HRMOTV $>2.0 . \mathrm{CO} ; 2$

Lynch, J. F., J. D. Irish, C. R. Sherwood, and Y. C. Agrawal, 1994: Determining suspended sediment particle size information from acoustical and optical backscatter measurements. Cont. Shelf Res., 14, 1139-1165, doi:10.1016/0278-4343(94)90032-9.

MacDonald, I., C. E. Vincent, P. D. Thorne, and B. D. Moate, 2013 : Acoustic scattering from a suspension of flocculated sediments. J. Geophys. Res. Oceans, 118, 2581-2594, doi:10.1002/ jgrc.20197.

MacMahan, J., J. Brown, and E. Thornton, 2009: Low-cost handheld global positioning system for measuring surf-zone currents. J. Coastal Res., 25, 744-754, doi:10.2112/08-1000.1.

Manning, A. J., and S. J. Bass, 2006: Variability in cohesive sediment settling fluxes: Observations under different estuarine tidal conditions. Mar. Geol., 235, 177-192, doi:10.1016/ j.margeo.2006.10.013.

Mikkelsen, O. A., P. S. Hill, and T. G. Milligan, 2006: Single-grain, microfloc and macrofloc volume variations observed with a LISST-100 and a digital floc camera. J. Sea Res., 55, 87-102, doi:10.1016/j.seares.2005.09.003.

Milligan, T. G., 1996: In situ particle (floc) size measurements with the Benthos 373 plankton silhouette camera. J. Sea Res., 36, 93-100, doi:10.1016/\$1385-1101(96)90777-7.

_ , and P. S. Hill, 1998: A laboratory assessment of the relative importance of turbulence, particle composition, and concentration in limiting maximal floc size and settling behaviour. J. Sea Res., 39, 227-241, doi:10.1016/S1385-1101(97)00062-2.

- , - and B. A. Law, 2007: Flocculation and the loss of sediment from the Po River plume. Cont. Shelf Res., 27, 309-321, doi:10.1016/j.csr.2006.11.008.

Mullarney, J. C., and S. M. Henderson, 2012: Lagrangian measurements of turbulent dissipation over a shallow tidal flat from pulse coherent acoustic Doppler profilers. Coastal Eng. Proc., 33, doi:10.9753/icce.v33.currents.49.

$\longrightarrow$, and - 2013: A novel drifter designed for use with a mounted acoustic Doppler current profiler in shallow environments. Limnol. Oceanogr. Methods, 11, 438-449, doi:10.4319/ lom.2013.11.438.

Oehler, F., G. Coco, M. O. Green, and K. R. Bryan, 2012: A datadriven approach to predict suspended-sediment reference concentration under non-breaking waves. Cont. Shelf Res., 46, 96-106, doi:10.1016/j.csr.2011.01.015.

Otsu, N., 1979: A threshold selection method from gray-level histograms. IEEE Trans. Syst. Man Cybern., 9, 62-66, doi:10.1109/ TSMC.1979.4310076.

Schmidt, W., B. Woodward, K. Millikan, R. Guza, B. Raubenheimer, and S. Elgar, 2003: A GPS-tracked surf zone drifter. J. Atmos. Oceanic Technol., 20, 1069-1075, doi:10.1175/1460.1. 
Shokr, M. E., 1991: Evaluation of second-order texture parameters for sea ice classification from radar images. J. Geophys. Res., 96, 10 625-10 640, doi:10.1029/91JC00693.

Singh, K. P., A. Basant, A. Malik, and G. Jain, 2009: Artificial neural network modeling of the river water quality-A case study. Ecol. Modell., 220, 888-895, doi:10.1016/j.ecolmodel.2009.01.004.

Singh, V., and S. M. Rao, 2005: Application of image processing and radial basis neural network techniques for ore sorting and ore classification. Miner. Eng., 18, 1412-1420, doi:10.1016/ j.mineng.2005.03.003.

Smith, S. J., and C. T. Friedrichs, 2011: Size and settling velocities of cohesive flocs and suspended sediment aggregates in a trailing suction hopper dredge plume. Cont. Shelf Res., 31 (Suppl.), S50-S63, doi:10.1016/j.csr.2010.04.002.

Thomson, J., 2012: Wave breaking dissipation observed with "SWIFT" drifters. J. Atmos. Oceanic Technol., 29, 1866-1882, doi:10.1175/JTECH-D-12-00018.1.

Traykovski, P., R. J. Latter, and J. D. Irish, 1999: A laboratory evaluation of the laser in situ scattering and transmissometery instrument using natural sediments. Mar. Geol., 159, 355-367, doi:10.1016/S0025-3227(98)00196-0.

van Leussen, W., 1999: The variability of settling velocities of suspended fine-grained sediment in the Ems estuary. J. Sea Res., 41, 109-118, doi:10.1016/S1385-1101(98)00046-X.

Welch, R. M., S. K. Sengupta, and D. W. Chen, 1988: Cloud field classification based upon high spatial resolution textural features: 1. Gray level co-occurrence matrix approach. J. Geophys. Res., 93, 12 663-12 681, doi:10.1029/JD093iD10p12663.

Wiles, P. J., T. P. Rippeth, J. H. Simpson, and P. J. Hendricks, 2006: A novel technique for measuring the rate of turbulent dissipation in the marine environment. Geophys. Res. Lett., 33, L21608, doi:10.1029/2006GL027050.

Winterwerp, J. C., 1998: A simple model for turbulence induced flocculation of cohesive sediment. J. Hydraul. Res., 36, 309326, doi:10.1080/00221689809498621.

Zedel, L., A. E. Hay, R. Cabrera, and A. Lohrmann, 1996: Performance of a single-beam pulse-to-pulse coherent Doppler profiler. IEEE J. Oceanic Eng., 21, 290-297, doi:10.1109/48.508159. 